\title{
Vulnerability Conditions in a Cohort of Men Who Have Sex with Men Who Engage in Chemsex in Barcelona City: a Cross-Sectional Study
}

\author{
Lorena De La Mora ${ }^{1}$ - Montserrat Laguno ${ }^{1}$ - Elisa De Lazzari ${ }^{1}$. Ainoa Ugarte ${ }^{1}$ - Lorna Leal ${ }^{1}$ - Berta Torres ${ }^{1}$. \\ Ana González-Cordón ${ }^{1}$. Alexy Inciarte ${ }^{1}$. Juan Ambrosioni ${ }^{1}$. Zoraida Escalante ${ }^{1}$. Ana Rodriguez ${ }^{1}$. \\ Esteban Martinez ${ }^{1}$. José L. Blanco ${ }^{1}$. Jordi Blanch ${ }^{2}$. Laia Miquel ${ }^{2}$. Jordi Bosch ${ }^{3}$. Duncan Short ${ }^{4}$. Josep Mallolas ${ }^{1}$. \\ Maria Martinez-Rebollar ${ }^{1}$ (ID
}

Accepted: 18 February 2022

(c) The Author(s) 2022

\begin{abstract}
Introduction Chemsex is a dynamic phenomenon with cultural variation. There is limited information about its prevalence and specific characteristics in our geographical area.

Methods In this cross-sectional study of a series of gay, bisexual, and other men who have sex with men (gbMSM) who engaged in chemsex and were attending the Hospital Clinic of Barcelona, Spain, between March 2018 and May 2019, we aimed to identify potential vulnerabilities and describe the profiles of individuals who engaged in chemsex in our site. Baseline clinical and epidemiological characteristics related to HIV, HCV, STIs, sexual practices, and drug consumption were evaluated. A sub-analysis considering vulnerability conditions was completed.

Results We included 161 participants: 67\% were migrants and 48\% were Latin American. A total of 150 participants were people living with HIV (PLWH), and 13\% had a detectable HIV viral load (VL). The prevalence of HCV infection was $37 \%$. Slamming practice was reported by $20 \%$ of the participants. Migrants from Latin America were younger, had a lower percentage of university education, and more frequently had detectable HIV-VLs and syphilis. HCV-positive participants reported more injecting drug use, versatile fisting practices, and syphilis. Slam users consumed more methamphetamine and mephedrone, had significantly higher HIV-VLs when detectable, and reported less sober sex.

Conclusion and Policy Implications We identified certain baseline characteristics of our chemsex cohort that may confer a profile of greater vulnerability, which must be addressed in a personalized way when attempting damage reduction and a global approach to the practice of chemsex at our site. Access to specialized and interdisciplinary services with cultural competence in the complexity of the phenomenon should be guaranteed to these individuals for better management.
\end{abstract}

Keywords Chemsex $\cdot$ Vulnerability conditions $\cdot$ MSM $\cdot$ HIV $\cdot$ HCV $\cdot$ STDs

\section{Introduction}

Maria Martinez-Rebollar

rebollar@clinic.cat

1 Infectious Diseases Service, HIV Unit, Hospital Clinic and IDIBAPS, University of Barcelona, Villarroel 170, 08036 Barcelona, Spain

2 Addiction Unit (GRAC). Psychiatry and Psychology Department, Hospital Clinic of Barcelona, IDIBAPS, CIBERSAM, University of Barcelona, Barcelona, Spain

3 Department of Microbiology, Hospital Clínic, University of Barcelona, ISGlobal, Barcelona, Spain

4 ViiV Healthcare, Brentford, Middlesex, UK
Chemsex is defined as the intentional use of recreational drugs before or during sexual encounters among gay, bisexual, and other men who have sex with men (gbMSM) to facilitate, enhance, and prolong sexual intercourse (Bourne et al., 2015a, b). It was established as a subset of sexualized substance use in the gay community and health sector less than a decade ago, with the distinction of the intentionality of drug use, the time factor, the engagement of new technologies, and the use of specific drugs such as mephedrone, crystal methamphetamine, and $\gamma$-hydroxybutyrate $/ \gamma$ butyrolactone (GHB/GBL) (Bourne et al., 2014, 2015a, b). Other drugs have been associated with chemsex, and their 
use can differ between and within cities, demonstrating the dynamics of the phenomenon and its cultural variation (Drückler et al., 2018; Latini et al., 2019; Schmidt et al., 2016).

The chemsex phenomenon has been a subject of study, motivated by the associations that have been described between drug use and other health issues in gbMSM (Maxwell et al., 2019; Mercer et al., 2016). Polydrug use has been associated with having condomless sex, group sex, and multiple sexual partners, in both HIV-positive and HIVnegative individuals (Daskalopoulou et al., 2014; for the EMIS Network et al., 2015); increased use of postexposure prophylaxis (PEP); and an increased risk of sexually transmitted diseases (STD), HIV, and HCV diagnoses (Sewell et al., 2018). In HIV-positive individuals, polydrug use may lead to difficulties with antiretroviral therapy (ART) adherence (Giorgetti et al., 2017; Hinkin et al., 2007). Although to a lesser extent, there is also evidence of potential mental health issues, substance disorders, and psychological and social impacts of problematic chemsex (Bourne \& Weatherburn, 2017; Bourne et al., 2015a, b; Hegazi et al., 2017). All this evidence suggests the need for special efforts to prevent these events (Mora, s. f.).

In the latest European MSM Internet Survey (EMIS2017) results, the HIV-positive gbMSM that represented Barcelona reported the highest prevalence of sexualized drug use (13.7\%) compared to other cities in Spain (Encuesta europea on-line para hombres que tienen sexo con hombres (EMIS-2017): Resultados en España, Ministerio de Sanidad, 2020 s. f.). Despite the fact that Barcelona is mentioned in different scenarios, there is scarce information on the specific profile of the population that engages in chemsex in our geographical area (Fernández-Dávila, 2017, s.f.; Mora, s. f.; Schmidt et al., 2016). The objective of this study was to characterize the individuals who engaged in chemsex and attended our hospital and analyse the potential vulnerability conditions of this population, with the purpose of defining a better strategy for the care continuum and a global approach.

\section{Methods}

\section{Study Design and Setting}

A descriptive cross-sectional study of a series of gbMSM (HIV-positive and HIV-negative) who practiced chemsex was carried out at the Barcelona Hospital Clinic (HCB), located in an area with a large gay population in Barcelona (see the Supplementary data). This study was part of an ongoing prospective study named the Care_ChemS_CliniC Study, (CSC Study) and was funded by an international grant from ViiV Healthcare through its Positive Pathways program. The study was approved by the HCB Ethics Committee.

\section{Study Population and Data Collection}

Between March 2018 and May 2019, individuals who attended the HCB and met the eligibility criteria were asked to participate (gbMSM, over 18 years of age, positive or negative HIV serostatus, and a history of drug use to intentionally enhance and prolong sexual experiences during the last year; for more information, see the Supplementary data). A medical history was obtained, including drug use and sexual behaviour information. A referral for the assessment of drug use and sexual advice was given to the participants (referred to the Chemsex Support service from the NGO Stop Sida (Mora, s. f.) and/or the Addiction Unit of Psychiatry of the HCB). The data of the referred individuals were reported. Participants were asked to complete a survey about the use of recreational drugs and sexual behaviour. The questionnaire was based on surveys and qualitative research, has previously been used with gbMSM, and was modified and agreed upon by experts in psychiatry from the HCB and psychologists from the NGO Stop Sida. Blood analysis, including HIV, HCV, and syphilis serologies; HCV-ARN for people with a previous HCV infection; and urine, pharyngeal, and rectal smear samples for STD screening were performed.

We conducted sub-analyses based on the variables that we found to be frequent in the baseline analysis and that could be considered vulnerability conditions, as they can cause greater sexual and mental health impacts for the patient. We have adapted the vulnerability definition that has already been described, in the context of previous studies, as conditions that influence a person's suffering from sexual and mental health problems, such as HIV, STDs and addictions (Ayres et al., 2006; Nichiata et al., 2008).

The variables we analysed were as follows: migration from Latin America (this ethnicity represents the majority of PLWH migrants in Spain) (Hernando Rovirola et al., 2014; Hernando et al., 2015; Ministerio de Sanidad, Consumo y Bienestar Social—Ciudadanos-Vigilancia epidemiológica, s. f.); HCV infection; use of injected drugs with sexual purposes (slamming); and HIV infection with a detectable HIVRNA viral load (VL) (> 50 copies $/ \mathrm{ml}$ ).

\section{Statistical Methods}

Qualitative variables are described as frequencies and percentages, and in the sub-analyses, they were compared between groups using the chi-square test or Fisher's exact test. Quantitative variables were summarized as the means and standard deviations (SDs) or as medians and interquartile ranges (IQRs); in the sub-analyses, they were compared 
between groups using the $t$ test or the Wilcoxon rank sum test in cases of skewed distributions. Network coincidence analysis based on the multidimensional scaling (MDS) algorithm was performed to study the combined use of the different drugs. The results were represented graphically using the MDS network diagram, where drugs are represented by circles with sizes that are directly proportional to their frequency, and are connected by three different patterns of lines according to the three levels of significance of the standardized residuals (derived from the frequency table): dotted lines, probable coincidence (0.5); dashed lines, statistically probable $(<0.05)$; and solid lines, statistically probable $(<0.01)$. The most preferred combinations of drugs are those represented with solid lines, followed by those with dashed lines and finally those with dotted lines. The drugs with the highest number of matches are located in the centre of the diagram; those that are less correlated tend to be located on the fringes of the space. Correlated drugs tend to be close in space. The statistical program used was Stata (StataCorp, 2019) Stata: Release 16. Statistical Software. College Station, TX: StataCorp LLC.).

\section{Results}

Of the $161 \mathrm{gbMSM}$ who engaged in chemsex who were included (see Fig. 1), 67\% were migrants and $48 \%$ were Latin American; 150 participants were PLWH and 13\% $(N=20)$ had a detectable HIV-VL. The prevalence of HCV infection was $37 \%(N=56)$, and $25 \%$ of these participants $(N=14)$ had an active HCV infection. A total of $13 \%(13 / 103)$ of the sample disclosed having worked as sex workers. Sociodemographic, clinical STD microbiology, and HIV characterization of the individuals are described in Table 1 and in the Supplementary data. Sexual behaviours and sexual practices are illustrated in Table 2 and in the Supplementary data.

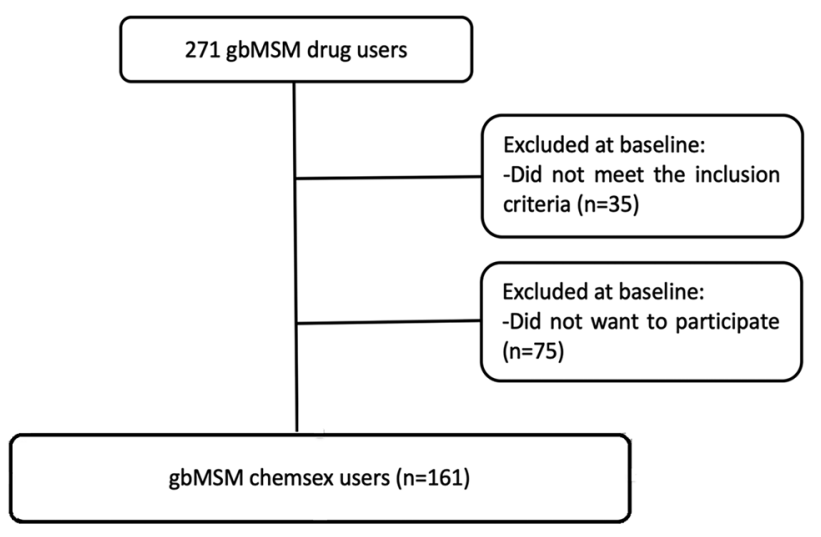

The substances used and their frequency of use are described in Fig. 2. The most consumed substances were phosphodiesterase type 5 inhibitors (erectile dysfunction drugs). The most frequently used drugs were methamphetamine (77\%) and GHB (76\%). Polydrug use was reported by $79(50 \%)$ participants. Figure 3 illustrates the most frequently used drug combinations and the most common drugs used by participants who reported polydrug consumption; erectile dysfunction drugs were the type of substance that was most commonly used in combination with other drugs (as they are located in the central part of the graph). GHB/GBL and methamphetamine were the most preferred drugs by mephedrone users. Ketamine was preferentially combined with ecstasy. The drug use characterization in this series of patients is shown in Table 3 and the Supplementary material. A total of $32(20 \%)$ individuals reported slamming; two $(6 \%)$ of them shared injection materials. Table 4 illustrates the main concerns for requesting help. Referrals for psychological/psychiatric support were offered to 77 individuals, of whom 57 accepted.

\section{Sub-analysis Comparing Groups by Origin (Latin Americans vs. Europeans)}

Latin American participants who engaged in chemsex were younger $(p<0.01)$, with a mean age of 36 years (SD 8); the percentage of Latin American participants with a university education was lower than that of European participants ( $33 \%$ vs. $51 \%$, respectively; $p=0.02$ ). Regarding HBV, the frequency of positive anti-HBs results was lower in Latin Americans (49/72, $68 \%$ vs. 61/74, 82\%, respectively; $p=0.04$ ) than in Europeans, but their frequency of positive anti-HBc results was higher $(25 / 72,35 \%$ vs. $15 / 74,20 \%$, respectively; $p=0.05$ ). The prevalence of positive syphilis nontreponemal serology was higher in the Latin American group than in the European group (50/72, 69\% vs. 36/74, $49 \%$, respectively; $p=0.01$ ). There was no difference between the groups in the prevalence of HCV. The prevalence of PLWH with a detectable VL was higher in migrants than in Latin Americans (15/72, 21\% vs. 5/73, respectively; $7 \%)(p=0.014)$. Regarding drug use, $34 \%$ of Latin Americans (23/67) did not remember the last time having sober sex compared to $18 \%$ of Europeans (13/58) $(p=0.03)$. A higher proportion of Europeans $(35 / 40,88 \%)$ admitted needing help in relation to drug use compared to Latin Americans $(27 / 41,66 \%)(p=0.02)$. However, a higher proportion of Latin Americans stated needing help in relation to possible STDs compared to Europeans (33/39, $85 \%$ vs. $22 / 36,61 \%$, respectively; $p=0.02$ ).

Fig. 1 Study population 
Table 1 Demographic and clinical characteristics of the study cohort

\section{Variable}

Demographic characteristics

\section{Demographic characteristies}

Age, years

Mean (SD)

Age, years

Region of origin $(N=159)$

Spain

Europe (w/o Spain)

$39(9)$

$n(\%)$

Latin America

$53(33 \%)$

$27(17 \%)$

$76(48 \%)$

Australia/Oceania

$1(1 \%)$

Asia

$1(1 \%)$

Africa

$1(1 \%)$

Period of arrival in Spain $(N=104)$

$<2010$

$50(48 \%)$

2010-2014

$15(14 \%)$

$\geq 2015$

$39(38 \%)$

Educational level $(N=144)$

No schooling completed

$2(1 \%)$

$5(3 \%)$

$75(52 \%)$

Secondary

$62(43 \%)$

\section{Clinical characteristics}

University

n (\%)

HIV $(N=160)$

HBsAg $(N=150)$

Anti-HBs $(N=150)$

Anti-HBc $(N=150)$

IgG anti-HAV $(N=126)$

Nontreponemal tests, VDRL* $(N=150)$

$\mathrm{IgG}$ anti-HCV $(N=150)$

$\operatorname{HCV}-A R N(N=56)$

\section{STDs data}

STD detected by PCR $(N=161)$

Chlamydia trachomatis

Neisseria gonorrhoeae

Mycoplasma genitalium

\section{Positive}

Positive

Positive

Positive

Positive

Positive

Positive

Positive

Test result

Negative

Positive

Not performed

Negative

Positive

Not performed

Negative

Positive

Not performed
$150(94 \%)$

$3(2 \%)$

$114(76 \%)$

$41(27 \%)$

$106(84 \%)$

$89(59 \%)$

$56(37 \%)$

$14(25 \%)$

\section{HIV data}

\section{Lymphocyte subpopulations}

$\mathrm{CD} 4+\mathrm{T}$ lymphocytes count $\left(\right.$ cells $\left./ \mathrm{mm}^{3}\right)(N=149)$

$\mathrm{CD} 8+\mathrm{T}$ lymphocytes count (cells $\left./ \mathrm{mm}^{3}\right)(N=148)$

CD4/CD8 ratio $(N=148)$

Viral load (VL)

VL HIV-1 PCR $(N=149)$

Detectable HIV VL (copies/mL) $(\mathrm{N}=20)$
Median (IQR)

$671(522 ; 862)$

$811(627.5 ; 1005.5)$

$0.8(0.6 ; 1.1)$

VL

n (\%)

Detectable

$20(13 \%)$

Undetectable*

$129(87 \%)$ 
Table 1 (continued)

HIV data

$4950(108.5 ; 40,550)$

$\operatorname{ART}(N=150)$

\section{Treatment}

Raltegravir and dolutegravir

Boosted PI and Elvitegravir/c

NNRTI

Other

Without treatment n $(\%)$

$23(15 \%)$

$50(33 \%)$

$36(24 \%)$

$39(26 \%)$

$2(1 \%)$

Anti-HBs hepatitis B surface antibody, anti-HBc hepatitis B core antibody, $A R T$ antiretroviral treatment, $H B s A g$ hepatitis B surface antigen, $I g G$ anti-HAV hepatitis A virus IgG antibody, $I g G$ anti-HCV hepatitis $\mathrm{C}$ virus IgG antibody, IQR interquartile range, $N N R T I$ non-nucleoside reverse transcriptase inhibitors, $P I$ protease inhibitors, $S T D$ sexually transmitted disease, $V L$ viral load

*Positive nontreponemal tests refer to individual's past clinical history

Table 2 Sexual behaviour of the study cohort

\begin{tabular}{|c|c|c|}
\hline \multicolumn{3}{|l|}{ Sexual partners } \\
\hline & \multicolumn{2}{|l|}{ Median $(I Q R)$} \\
\hline Sexual partners, last 3 months $(N=141)$ & \multicolumn{2}{|l|}{$20(10 ; 30)$} \\
\hline Reachable sexual partners, last 3 months $(N=118)$ & \multicolumn{2}{|l|}{$8(3 ; 15)$} \\
\hline Sexual partners, last 12 months $(N=107)$ & \multicolumn{2}{|l|}{$40(10 ; 100)$} \\
\hline \multicolumn{3}{|l|}{ Sexual practices (during last 3 months) } \\
\hline Variable & Summary statistics & $n(\%)$ \\
\hline \multirow[t]{3}{*}{ Anal sex $(N=145)$} & Unprotected & $82(57 \%)$ \\
\hline & Protected & $8(6 \%)$ \\
\hline & Sometimes & $55(38 \%)$ \\
\hline \multirow[t]{3}{*}{ Oral sex $(N=146)$} & Unprotected & $104(71 \%)$ \\
\hline & Protected & $8(5 \%)$ \\
\hline & Sometimes & $34(23 \%)$ \\
\hline \multirow[t]{6}{*}{ Double penetration $(N=161)$} & No & $88(55 \%)$ \\
\hline & N/A & $1(1 \%)$ \\
\hline & Yes & $72(45 \%)$ \\
\hline & Unprotected & $55(76 \%)$ \\
\hline & Protected & $3(4 \%)$ \\
\hline & Sometimes protected & $14(19 \%)$ \\
\hline \multirow[t]{6}{*}{ Fisting $(N=161)$} & No & $99(61 \%)$ \\
\hline & N/A & $1(1 \%)$ \\
\hline & Yes & $61(38 \%)$ \\
\hline & Unprotected & $28(46 \%)$ \\
\hline & Protected & $11(18 \%)$ \\
\hline & Sometimes protected & $22(36 \%)$ \\
\hline \multirow[t]{6}{*}{ Sexual toys use $(N=161)$} & No & $92(57 \%)$ \\
\hline & N/A & $1(1 \%)$ \\
\hline & Yes & $68(42 \%)$ \\
\hline & Unprotected & $44(65 \%)$ \\
\hline & Protected & $4(6 \%)$ \\
\hline & Sometimes protected & $20(29 \%)$ \\
\hline
\end{tabular}


Fig. 2 Individual drug use frequency in the study cohort

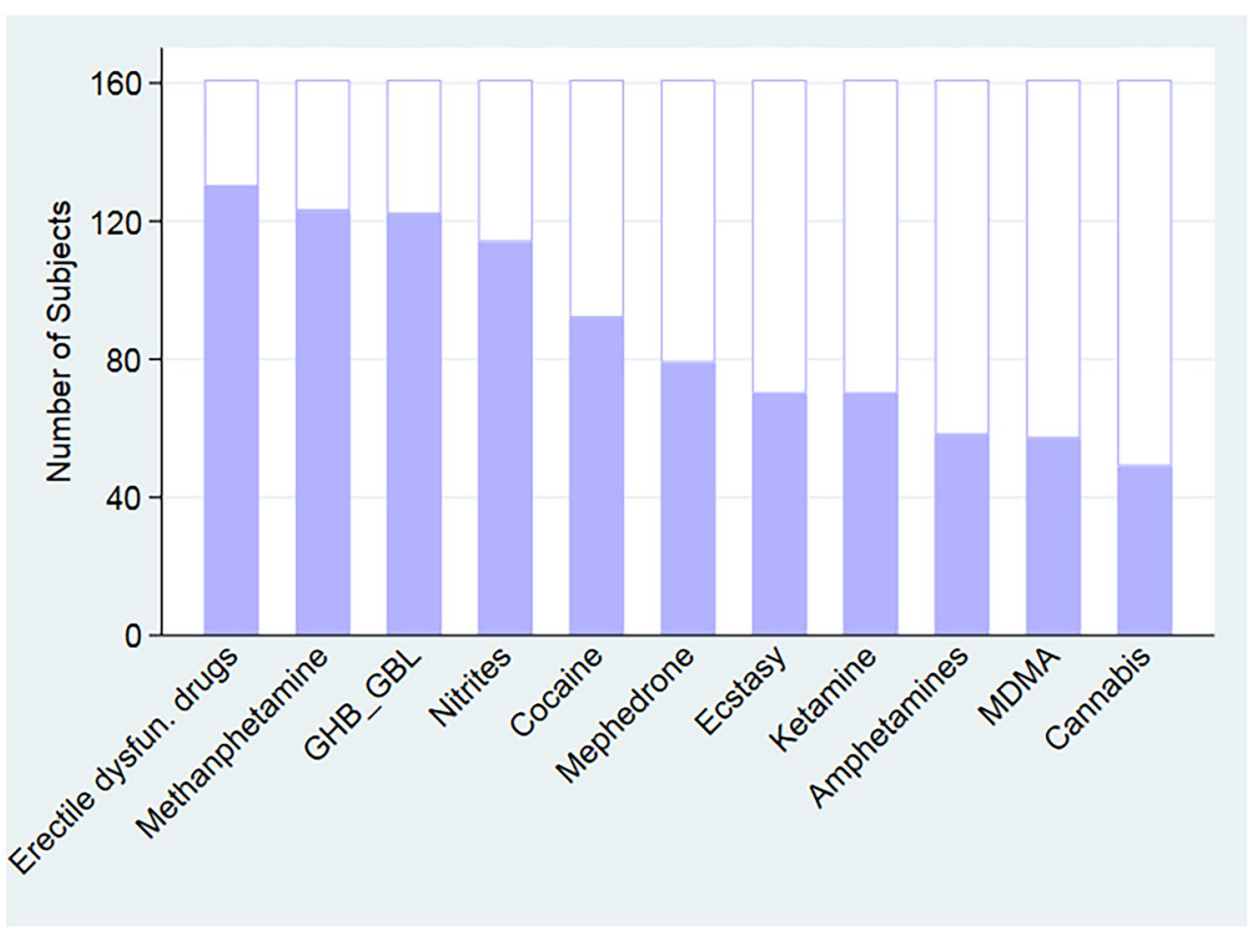

Fig. 3 Network graph of the drug combinations during chemsex. The multidimensional scaling network graph represents the drug combinations. Drugs are represented by circles with size directly proportional to their frequency, and they are connected by three different patterns of lines according to the three levels of significance of the standardized residuals (derived from the frequency table): dotted line, probable coincidence (0.5); dashed line, statistically probable $(<0.05)$; solid line, statistically probable $(<0.01)$. The most preferred combinations of drugs are those represented with solid lines, followed by those with dashed lines and finally dotted ones. In the centre of the diagram, there are the drugs with the highest number of matches, and the less correlated tend to be located on the fringes of the space. Besides, correlated drugs tend to be close in space

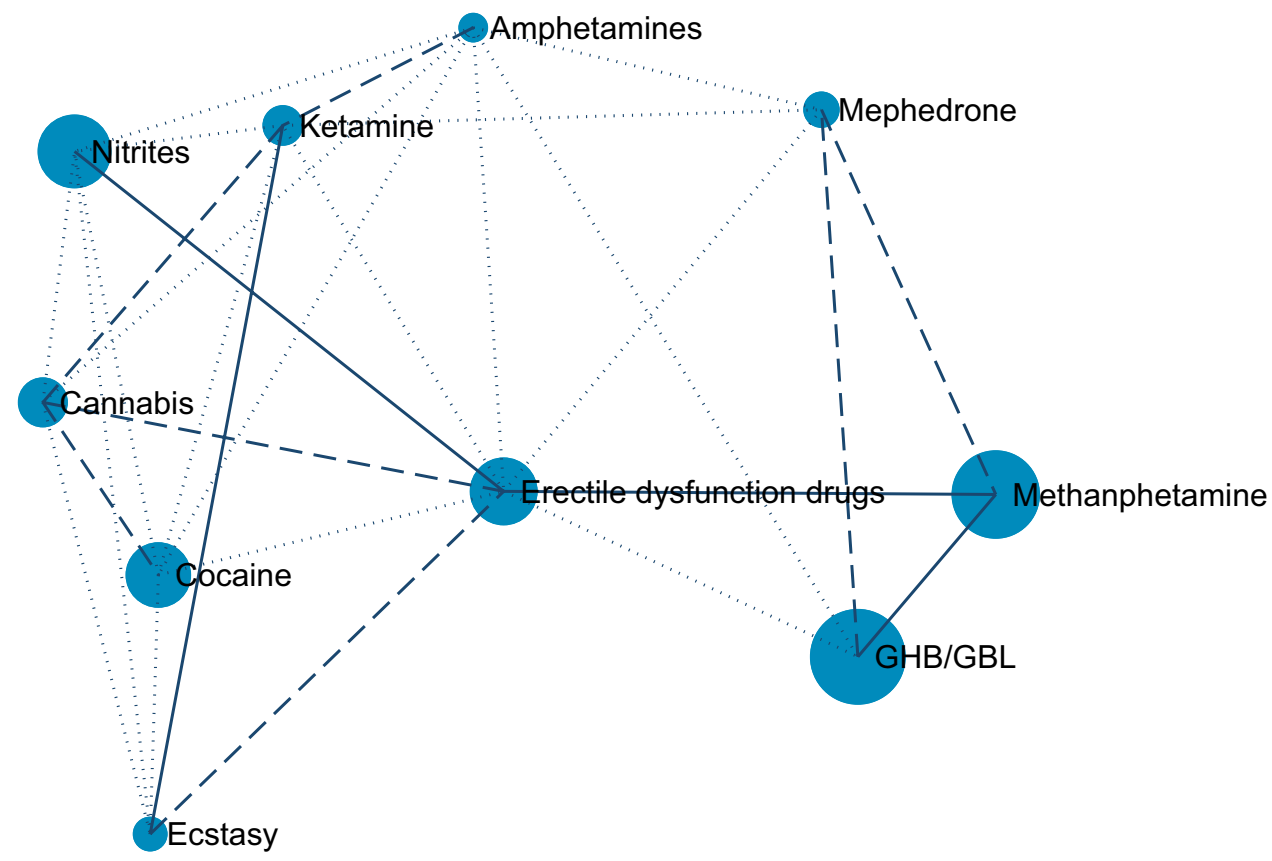

MDS coordinates 
Table 3 Drug use characterization (during last year)

Route of drug administration

Oral $(N=158)$

Inhaled $(N=159)$

$134(88 \%)$

Sniffed $(N=159)$

$111(70 \%)$

Sublingual $(N=158)$

$16(10 \%)$

Rectal $(N=160)$

$47(30 \%)$

Injecting or slamming $(N=159)$

$32(20 \%)$

Sharing venepuncture material if slamming $(N=30)$

$2(6 \%)$

Use of sterile material if slamming $(N=26)$

Frequency of drug use

Every day $(N=155)$

Every week $(N=157)$

Every month $(N=156)$

Number of drugs used

1 drug $(N=157)$

2 drugs $(N=157)$

Poly drug use* $(N=157)$

Other factors related to drug use

Individuals who do not remember the last time of sexual intercourse without drugs $(N=142)$

*consumption of $\geq 3$ drugs

\section{Sub-analysis Comparing Groups by HCV Status (Positive vs. Negative)}

We defined the individuals with either detectable HCV-RNA or IgG-positive serology as $\mathrm{HCV}$-positive. A higher prevalence of positive syphilis serology was detected in HCVpositive participants $(40 / 65,71 \%)$ than in HCV-negative participants $(49 / 94,52 \%)(p=0.01)$. Concerning drug use, $32 \%$

Table 4 Concerns and reasons for requesting help

\begin{tabular}{lll}
\hline & Variable & $\boldsymbol{n}(\boldsymbol{\%})$ \\
\hline $\begin{array}{l}\text { Concern } \\
\begin{array}{l}\text { Concern about use of drugs in sexual con- } \\
\quad \text { text }(N=154)\end{array}\end{array}$ & Yes & $118(77 \%)$ \\
$\begin{array}{l}\text { Concern about drug use }(N=113) \\
\text { Concern about sexuality }(N=108)\end{array}$ & Yes & $77(68 \%)$ \\
Concern about STDs $(N=107)$ & Yes & $65(60 \%)$ \\
Need for help & Yes & $86(80 \%)$ \\
$\begin{array}{l}\text { Do you think you need HELP? }(N=153) \\
\text { In relation to drugs use }(N=83)\end{array}$ & Yes & $92(60 \%)$ \\
In relation to sexuality $(N=75)$ & Yes & $63(76 \%)$ \\
In relation to possible STD $(N=77)$ & Yes & $40(53 \%)$ \\
\hline
\end{tabular}

(18/56) of the HCV-positive participants reported slamming compared to $13 \%$ (12/93) of the HCV-negative individuals $(p=0.007)$, and only one of them reported sharing injection materials. The HCV-positive group reported a higher prevalence of practising versatile fisting than the HCV-negative group (12/22, $55 \%$ vs. $10 / 36,28 \%$, respectively; $p=0.04)$; there were no differences between the groups regarding other risky sexual practices.

\section{Sub-analysis Comparing Groups by Injected Drug Use (Slamming vs. Non-slamming)}

The slamming group had a higher prevalence of HCV-positive serology $(18 / 30,60 \%$ vs. $38 / 119,32 \%$, respectively; $p=0.04$ ) and active HCV infections (positive HCV-RNA $(8 / 18,44 \%$ vs. $6 / 38,16 \%$, respectively; $p=0.04)$ than the non-slamming group. Although the percentage of detectable HIV-VLs between the slamming and non-slamming groups was not statistically significant $(6 / 30,20 \%$ vs. $14 / 118,12 \%$, respectively; $p=0.24$ ), we observed that among those with a detectable VL, HIV RNA was significantly higher in the slamming group $(20,285$ copies/mL $(8,700 ; 142,000))$ vs. (450.5 copies/mL $(87 ; 20,500)$, respectively; $p=0.048)$. The individuals who were referred for practising slamming 
reported more frequent consumption of methamphetamine $(31 / 32,97 \%$ vs. $91 / 127,72 \%$, respectively; $p=0.002)$ and mephedrone (22/32, $69 \%$ vs. $56 / 127,44 \%$, respectively; $p=0.01$ ) than those who did not practice slamming. Moreover, $43 \%$ of the individuals who used intravenous drugs did not remember the last time having sexual intercourse without drug use, compared with $21 \%$ of the individuals who did not use intravenous drugs $(p=0.018)$. Although there was no statistically significant difference, $70 \%$ of the individuals in the slamming group reported unprotected anal sex, compared to 53\% of those in the non-slamming group. Double penetration was more frequent in the slamming group than in the non-slamming group $(21 / 32,66 \%$ vs. $51 / 127,40 \%$, respectively).

\section{Sub-analysis Comparing Groups by VL (PLWH with an Undetectable VL vs. PLWH with a Detectable VL)}

In the group of PLWH with an undetectable VL, 78\% reported that their sexual partners were reachable, compared to 50\% in the group of PLWH with a detectable VL $(p=0.01)$. The mean CD4 + T lymphocyte count and CD4/ $\mathrm{CD} 8$ ratio were significantly higher in PLWH with an undetectable VL ( 692 cells $/ \mathrm{mL}$ and 0.9 ; vs. 434 cells $/ \mathrm{mm}^{3}$ and 0.5 , respectively; $p<0.001$ ). Nonprotected fisting practices were reported in $37 \%$ of the PLWH with an undetectable VL and by all the PLWH with a detectable VL $(p=0.003)$.

\section{Discussion}

Our study illustrates the characteristics of a series of individuals who engage in chemsex in Barcelona, and the results suggest risk and vulnerability factors that might be considered in a multidisciplinary approach to chemsex. This study is unique because we described the first single-centre cohort in Spain that was exclusively comprised of individuals who engaged in chemsex. Furthermore, this study is relevant since we carried out a multidisciplinary approach within a specific in-hospital program to better understand the profile of individuals who engage in chemsex in our environment and establish targeted health strategies.

In our cohort, there was a high prevalence of migrants (67\%), especially from Latin America (48\%), in contrast to previously published chemsex studies in Madrid, Spain, in which $74 \%$ of individuals who engaged in chemsex were Spanish-born. Nevertheless, our results agree with the latest published results from the EMIS-2017, where migrants in Spain represented a subgroup with a high prevalence of sexualized drug use (Encuesta europea on-line para hombres que tienen sexo con hombres (EMIS-2017): Resultados en España, Ministerio de Sanidad, 2020 s. f.). Furthermore,
$38 \%$ of the Latin American migrants in our cohort arrived in Barcelona from 2015 on, which coincides with the rise of the chemsex phenomenon in our city (FernándezDávila, 2017 s. f.); this synchronicity should be explored. Although it is assumed that the majority of HIV diagnoses are acquired by migrants in their home countries, especially if they come from areas with a high HIV prevalence, there is growing evidence of individuals contracting HIV after migration, and the risk in gbMSM is of particular concern (Fakoya et al., 2015). They reported significantly less sober sex and fewer worries about drug consumption. The bureaucratic and cultural limitations that migrants encounter when accessing the health system and medication may limit the understanding of HIV and the importance of adherence to ART. The irregular legal-administrative situation, lower level of education, need for socialization, stigma of HIV and homophobia experienced in their countries, and poorer social network and family support of many migrants might lead to problematic chemsex practices, conferring greater vulnerability to this subgroup (Fernández-Dávila, 2017 s. f.; Weatherburn et al., 2017).

We found that $13 \%$ of the individuals identified themselves as sex workers at baseline. This profile can involve more elements of vulnerability because drug consumption, rest hours, and the pressure to consume are higher and more irregular depending on the customers (Abordaje del fenómeno del chemsex. Secretaría del Plan Nacional sobre el Sida. Ministerio de Sanidad, 2020 s. f.); this finding in our cohort must also be addressed in a personalized way to facilitate access to health care, since some of these individuals have high geographical mobility, to minimize the impact of highly frequent drug use and sexual practices.

The high prevalence of hepatitis C (37\%) in this series of individuals who engaged in chemsex is outstanding, exceeding the range of 2.8-30\% reported in other studies (Bui et al., 2018; Hegazi et al., 2017; Hopwood et al., 2015; Pakianathan et al., 2018). This subgroup reported significantly more injecting drug use, more versatile fisting practices and more syphilis coinfections. Only one $\mathrm{HCV}$-infected participant reported sharing syringes. Based on this, variables other than sharing injection materials, such as high-risk sexual practices, may be related risk factors for HCV infection. This hypothesis is supported by other publications (Berenguer et al., 2019; Martínez-Rebollar et al., 2015), and individuals who engage in chemsex are a target population to tailor strategies to achieve HCV microelimination (Martínez-Rebollar et al., 2021).

The majority of individuals who engaged in chemsex in this series were PLWH, and 20 of them (13\%) had a detectable HIV-RNA-VL, while the prevalence of a detectable VL in our HCB PLWH cohort was 6\%. It should be noted that two of these individuals were treatment naive and recently diagnosed. Therefore, this is another vulnerability condition 
to consider within risk management. These individuals reported significantly more unprotected anal sex and fisting and less control in reaching their sexual partners. We believe it is important to identify this subgroup, assess their needs, and address the factors that can influence treatment adherence. Harm reduction strategies that encourage selfcare within the practice of chemsex, such as taking ART, among other described measures (Stardust et al., 2018), are essential to reduce the potential impact on these individuals' health and on HIV transmission.

Regarding the prescribed ART for these individuals who engaged in chemsex, one-third were treated with boostedintegrase inhibitors or protease inhibitors at the time of inclusion. It is important to discuss the interactions of ART and drugs with these individuals. To date, basic pharmacological information about drug-drug interactions (DDIs) between ART and recreational drugs has been published (Bracchi et al., 2015; Giorgetti et al., 2017; Kumar et al., 2015), but there is little information on the clinical implications of DDIs in real life (Harrington et al., 1999; Mayer et al., 2006; Muirhead et al., 2000).

A significant number of individuals with asymptomatic STDs were detected at baseline, with syphilis and Neisseria gonorrhoea predominating. It is also remarkable that a minority of our patients reported using protection during sex, similar to previous publications (Bourne et al., 2014; Daskalopoulou et al., 2014; Sewell et al., 2018; Yu et al., 2015).

Concerning drug-related behaviours, $50 \%$ of our patients reported polydrug use, similar to the $47 \%$ reported in the ASTRA study (Daskalopoulou et al., 2014). Polydrug use has been associated with sexual risk behaviours in previous studies (Glynn et al., 2018; Sewell et al., 2017). The use of methamphetamine, GHB, and cocaine represented a high prevalence in our study, especially the combination of the first two drugs, and differed from patterns in other geographical areas (Frankis et al., 2018; González-Baeza et al., 2018). Additionally, the prevalence of slamming differed between series: $20 \%$ of the patients in our cohort reported slamming, compared to $16 \%$ in the U-SEX study (González-Baeza et al., 2018), and approximately 13.5 to $18.1 \%$ in a series of gbMSM who attended sexual health clinics in the UK (Hegazi et al., 2017; Pakianathan et al., 2018). More than $70 \%$ of the individuals who engaged in chemsex expressed concerns and needs for help regarding drug use, their sexuality and STDs; a percentage clearly higher than the $20.6 \%$ was reported in the EMIS-17 study (Encuesta europea on-line para hombres que tienen sexo con hombres (EMIS-2017): Resultados en España, Ministerio de Sanidad, 2020 s. f.) and $31 \%$ of patients in a study performed in Dublin disclosed needing help for chemsex (Glynn et al., 2018). These data lead us to consider the need to reinforce the multidisciplinary management of chemsex.
Slamming is a sexual risk practice that may lead to another vulnerability condition that we found, since participants who engaged in this practice reported significantly higher positive $\mathrm{HCV}$ serology, active HCV infections, and higher HIV-VLs when detectable. People who inject drugs having both HCV and HIV detectable VLs implies a public health problem, which has been described in other settings, and are primary contributors to morbidity and mortality as a consequence of injected drug use (Degenhardt et al., 2017). This group reported the most frequent unprotected anal intercourse, similar to the Australian FLUX study results (Bui et al., 2018), and more sexual risk practices, such as double penetration. Methamphetamine and mephedrone were the most commonly injected drugs in our sample, comparable with data from the EMIS-17 (Encuesta europea on-line para hombres que tienen sexo con hombres (EMIS-2017): Resultados en España, Ministerio de Sanidad, 2020 s. f.). These drugs, particularly methamphetamine, are stimulating, are disinhibitory, and increase libido. Significantly, slamming practices were related to less sober sex. Previous studies have established significantly higher sexual risk behaviours in gbMSM who use methamphetamine (Hirshfield et al., 2004; Hoenigl et al., 2016), and slamming is closely associated with current psychiatric disorders and severe drugrelated and psychiatric symptoms (Dolengevich-Segal et al., 2019).

\section{Study Limitations}

One of the limitations of this study is that there may be a potential bias between the total cohort of patients living with HIV followed in our hospital and the total number of individuals who engaged in chemsex who were identified and approached for the study. The systematic questioning about substance use at each visit was not standardized, and potential individuals who engaged in chemsex may have been missed.

However, we must emphasize that carrying out this study has allowed us to standardize and update the questions on substance use for all the patients we follow. A second limitation could be the use of self-completed questionnaires, which limited data analysis. Finally, this was a cross-sectional study, but we are collecting follow-up data to be able to study the impact on the incidence of new HIV, HCV, and other STI infections in this group, which will be the main objective of subsequent analyses with this cohort.

\section{Conclusions}

Our results suggest that gbMSM who practice chemsex in our geographical area show a high prevalence of asymptomatic STIs, HCV infections, polydrug use with 
methamphetamine, and GHB, which are the most frequently used drugs, and high-risk sexual practices.

The majority of the participants had concerns and needs about drug management consumption, their sexual life, and STDs.

We have identified a specific profile with certain vulnerabilities that must be addressed in a personalized way when attempting damage reduction and needs tailored follow-up.

We believe that a multidisciplinary and syndemic approach to chemsex practice must be personalized. It is pertinent to generate more scientific knowledge to adapt interventions to the different individual profile needs since they are geographically and temporally different, and it is essential to pay close attention to the most vulnerable subgroups.

\section{Social and Public Policy Implications}

Access to specialized and interdisciplinary services with cultural competence in the complexity of the phenomenon should be guaranteed to these individuals for better management.

Supplementary Information The online version contains supplementary material available at https://doi.org/10.1007/s13178-022-00702-1.

Acknowledgements We would especially like to thank the NGO Stopsida and its Chemsex Support Service for all the collaboration in this particular study and in our daily clinical practice. The possibility of working jointly and in a multidisciplinary team with the community benefits everyone: health professionals by improving our cultural competence, the community by facilitating access and communication with health institutions and people who engage in chemsex by offering a global and syndemic approach when needed.

We would also like to thank the participants in the study for their availability and for the trust they placed in us, allowing us to address intimate and sensitive issues that we have always tried to approach without stigma and without judgement. Thank you for helping us to improve our work.

Author Contribution L.D.M. and M.L. contributed equally to the study. J.M. and M.M.R contributed equally to the study. J.M and M.M.R designed the study. D.S. was a ViiV representative who collaborated in the study design. L.D.M, M.L, A.U, L.L, B. T., A.G.C., A.I., J.A, Z.E, A.R, E.M., J.L.B., J.B., L.M., J.M., and M.M.R recruited patients for the study. J. Bosch analysed all microbiological samples from all the participants. L.D.M., E.D.L., J.M., and M.M.R analysed and interpreted the data. L.D.M., M.L., J.M., and M.M.R were involved in drafting the manuscript. All authors were involved in reviewing the manuscript and approved the final version.

Funding This work was supported by a grant from ViiV Healthcare through its Positive Pathways program.

\section{Declarations}

Conflict of Interest L.D.M. has received fees to give lectures from Gilead, MSD, ViiV, AbbVie, and Janssen-Cilag. M.L. received fees to give lectures from Gilead, MSD, ViiV, AbbVie, and Janssen-Cilag.
A.U. has received fees to give lectures from Gilead, ViiV, and JanssenCilag. L.L. and B.T. have received fees to give lectures from Gilead, MSD, ViiV, AbbVie, and Janssen-Cilag. A.G.C. has received fees to give lectures and advisory board from Gilead, MSD, ViiV, AbbVie, and Janssen-Cilag. A.I. has received educational grants from MSD and Gilead. JA has participated in advisory boards and received consulting honoraria, research grants, or both, from Gilead Sciences, Janssen Pharmaceuticals, and ViiV Healthcare, all outside of this work. E.M. has received honoraria for lectures or advisory boards from Gilead and Janssen and his institution has received research grants from MSD and ViiV. J.L.B. has received honoraria for lectures or advisory boards from Gilead, Janssen, MSD. L.M. has received honoraria for lectures from Lundbeck, Gilead, and Neuraxpharm. J.B. has received honoraria for lectures or advisory boards from Ferrer Internacional, Gilead, Janssen, MSD, and ViiV. DS is an employee of ViiV Healthcare and shareholder of GlaxoSmithKline. J.M. has received honoraria, speakers' fees, consultant fees, or funds for research from MSD, Roche, Boehringer-Ingelheim, ViiV, Gilead, Janssen, BMS, AbbVie. M.M.R. has received fees to give lectures from Gilead, MSD, ViiV, AbbVie, and Janssen-Cilag. The authors have no other relevant affiliations or financial involvement with any organization or entity with a financial interest in or financial conflict with the subject matter or materials discussed in the manuscript apart from those disclosed. E.D.L. Z.E., A. R, and $\mathbf{J}$. Bosch have nothing to disclose.

Open Access This article is licensed under a Creative Commons Attribution 4.0 International License, which permits use, sharing, adaptation, distribution and reproduction in any medium or format, as long as you give appropriate credit to the original author(s) and the source, provide a link to the Creative Commons licence, and indicate if changes were made. The images or other third party material in this article are included in the article's Creative Commons licence, unless indicated otherwise in a credit line to the material. If material is not included in the article's Creative Commons licence and your intended use is not permitted by statutory regulation or exceeds the permitted use, you will need to obtain permission directly from the copyright holder. To view a copy of this licence, visit http://creativecommons.org/licenses/by/4.0/.

\section{References}

Abordaje del fenómeno del chemsex, Secretaría del Plan Nacional sobre el Sida, Ministerio de Sanidad. (2020). (s. f.). https://www. sanidad.gob.es/ciudadanos/enfLesiones/enfTransmisibles/sida/ chemSex/docs/CHEMSEX._ABORDAJE.pdf. Accessed March 2021

Berenguer, J., Gil-Martin, Á., Jarrin, I., Montes, M. L., Domínguez, L., Aldámiz-Echevarría, T., Téllez, M. J., Santos, I., Troya, J., Losa, J. E., Serrano, R., De Guzmán, M. T., Calvo, M. J., \& GonzálezGarcía, J. J. (2019). Reinfection by hepatitis C virus following effective all-oral direct-acting antiviral drug therapy in HIV/hepatitis C virus coinfected individuals. AIDS, 33(4), 685-689. https:// doi.org/10.1097/QAD.0000000000002103

Bourne, A., Reid, D., Hickson, F., Torres Rueda, S., \& Weatherburn, P. (2014). The Chemsex study: Drug use in sexual settings among gay \& bisexual men in Lambeth, Southwark \& Lewisham. London: Sigma Research, London School of Hygiene \& Tropical Medicine. (s. f.). http://researchonline.1shtm.ac.uk/2197245/. Accessed March 2021

Bourne, A., Reid, D., Hickson, F., Torres-Rueda, S., Steinberg, P., \& Weatherburn, P. (2015a). "Chemsex" and harm reduction need among gay men in South London. International Journal of Drug Policy, 26(12), 1171-1176. https://doi.org/10.1016/j.drugpo.2015. 07.013 
Bourne, A., Reid, D., Hickson, F., Torres-Rueda, S., \& Weatherburn, P. (2015b). Illicit drug use in sexual settings ('chemsex') and HIV/STI transmission risk behaviour among gay men in South London: Findings from a qualitative study: Table 1. Sexually Transmitted Infections, 91(8), 564-568. https://doi.org/10.1136/ sextrans-2015-052052

Bourne, A., \& Weatherburn, P. (2017). Substance use among men who have sex with men: Patterns, motivations, impacts and intervention development need. Sexually Transmitted Infections, 93(5), 342-346. https://doi.org/10.1136/sextrans-2016-052674

Bracchi, M., Stuart, D., Castles, R., Khoo, S., Back, D., \& Boffito, M. (2015). Increasing use of "party drugs" in people living with hiv onantiretrovirals: a concern for patient safety. AIDS, 29, 15851592. https://doi.org/10.1097/QAD.0000000000000786.

Bui, H., Zablotska-Manos, I., Hammoud, M., Jin, F., Lea, T., Bourne, A., Iversen, J., Bath, N., Grierson, J., Degenhardt, L., Prestage, G., \& Maher, L. (2018). Prevalence and correlates of recent injecting drug use among gay and bisexual men in Australia: Results from the FLUX study. International Journal of Drug Policy, 55, 222-230. https://doi.org/10.1016/j.drugpo.2018.01.018

de Ayres, J. R., \& C. M., Paiva, V., França, I., Gravato, N., Lacerda, R., Della Negra, M., Marques, H. H. de S., Galano, E., Lecussan, P., Segurado, A. C., \& Silva, M. H. (2006). Vulnerability, human rights, and comprehensive health care needs of young people living with HIV/AIDS. American Journal of Public Health, 96(6), 1001-1006. https://doi.org/10.2105/AJPH.2004.060905.

Daskalopoulou, M., Rodger, A., Phillips, A. N., Sherr, L., Speakman, A., Collins, S., Elford, J., Johnson, M. A., Gilson, R., Fisher, M., Wilkins, E., Anderson, J., McDonnell, J., Edwards, S., Perry, N., O’Connell, R., Lascar, M., Jones, M., Johnson, A. M., \& Lampe, F. C. (2014). Recreational drug use, polydrug use, and sexual behaviour in HIV-diagnosed men who have sex with men in the UK: Results from the cross-sectional ASTRA study. The Lancet HIV, 1(1), e22-e31. https://doi.org/10.1016/S2352-3018(14) 70001-3

Degenhardt, L., Peacock, A., Colledge, S., Leung, J., Grebely, J., Vickerman, P., Stone, J., Cunningham, E. B., Trickey, A., Dumchev, K., Lynskey, M., Griffiths, P., Mattick, R. P., Hickman, M., \& Larney, S. (2017). Global prevalence of injecting drug use and sociodemographic characteristics and prevalence of $\mathrm{HIV}, \mathrm{HBV}$, and $\mathrm{HCV}$ in people who inject drugs: A multistage systematic review. The Lancet Global Health, 5(12), e1192-e1207. https://doi.org/10.1016/S2214-109X(17)30375-3

Dolengevich-Segal, H., Gonzalez-Baeza, A., Valencia, J., ValenciaOrtega, E., Cabello, A., Tellez-Molina, M. J., Perez-Elias, M. J., Serrano, R., Perez-Latorre, L., Martin-Carbonero, L., Arponen, S., Sanz-Moreno, J., De la Fuente, S., Bisbal, O., Santos, I., Casado, J. L., Troya, J., Cervero-Jimenez, M., Nistal, S., on Behalf of the U-SEX GESIDA 9416 Study. (2019). Drug-related and psychopathological symptoms in HIV-positive men who have sex with men who inject drugs during sex (slamsex): Data from the U-SEX GESIDA 9416 Study. PLoS One, 14(12), e0220272. https://doi. org/10.1371/journal.pone.0220272

Drückler, S., van Rooijen, M. S., \& de Vries, H. J. C. (2018). Chemsex among men who have sex with men: a sexualized drug use survey among clients of the sexually transmitted infection outpatientclinic and users of a gay dating app in Amsterdam, the Netherlands. Sexually Transmitted Diseases, 45(5), 325-331. https://doi. org/10.1097/OLQ.0000000000000753.

Encuesta europea on-line para hombres que tienen sexo con hombres (EMIS-2017): Resultados en España, Ministerio de Sanidad. (2020). (s. f.). https://www.sanidad.gob.es/ciudadanos/enfLesiones/ enfTransmisibles/sida/docs/EMIS_Report_07052020.pdf. Accessed March 2021

Fakoya, I., Álvarez-del Arco, D., Woode-Owusu, M., Monge, S., RiveroMontesdeoca, Y., Delpech, V., Rice, B., Noori, T., Pharris, A., AmatoGauci, A. J., del Amo, J., \& Burns, F. M. (2015). A systematic review of post-migration acquisition of HIV among migrants from countries with generalised HIV epidemics living in Europe: Mplications for effectively managing HIV prevention programmes and policy. BMC Public Health, 15(1), 561. https://doi.org/10.1186/s12889-015-1852-9

Fernández-Dávila, P. (2017) Consumo de drogas y su relación con el sexo: Escuchando las voces de un grupo de hombres gais y bisexuales de la ciudad de Barcelona que practican ChemSex. Barcelona: Stop Sida, CEEISCAT y Subdirecció General de Drogodependències-Agència de Salut Pública de Catalunya. (s.f.). https://stopsida. org/wp-content/uploads/2018/11/Informe-estudio-cualitativoChemSex.pdf. Accessed March 2021

Frankis, J., Flowers, P., McDaid, L., \& Bourne, A. (2018). Low levels of chemsex amongst men who have sex with men, but high levels of risk amongst men who engage in chemsex: Analysis of a cross-sectional online survey across four countries. Sexual Health, 15(2), 144-150. https://doi.org/10.1071/SH17159

Giorgetti, R., Tagliabracci, A., Schifano, F., Zaami, S., Marinelli, E., \& Busardò, F. P. (2017). When "Chems" meet sex: a rising phenomenon called "ChemSex". Current Neuropharmacology, 15(5). https://doi.org/10.2174/1570159X15666161117151148

Glynn, R. W., Byrne, N., O’Dea, S., Shanley, A., Codd, M., Keenan, E., Ward, M., Igoe, D., \& Clarke, S. (2018). Chemsex, risk behaviours and sexually transmitted infections among men who have sex with men in Dublin, Ireland. International Journal of Drug Policy, 52, 9-15. https://doi.org/10.1016/j.drugpo.2017.10.008

González-Baeza, A., Dolengevich-Segal, H., Pérez-Valero, I., Cabello, A., Téllez, M. J., Sanz, J., Pérez-Latorre, L., Bernardino, J. I., Troya, J., De La Fuente, S., Bisbal, O., Santos, I., Arponen, S., Hontañon, V., Casado, J. L., Ryan, P., \& the U-SEX GESIDA 9416 Study. (2018). Sexualized Drug Use (Chemsex) Is Associated with High-Risk Sexual Behaviors and Sexually Transmitted Infections in HIV-Positive Men Who Have Sex with Men: Data from the U-SEX GESIDA 9416 Study. AIDS Patient Care and STDs, 32(3), 112-118. https://doi.org/10.1089/apc.2017.0263

Harrington, R. D., Woodward, J. A., Hooton, T. M., \& Horn, J. R. (1999). Life-Threatening Interactions Between HIV-1 Protease Inhibitors and the Illicit Drugs MDMA and $\gamma$-Hydroxybutyrate. Archives of Internal Medicine, 159(18), 2221-2224. https://doi. org/10.1001/archinte.159.18.2221

Hegazi, A., Lee, M., Whittaker, W., Green, S., Simms, R., Cutts, R., Nagington, M., Nathan, B., \& Pakianathan, M. (2017). Chemsex and the city: Sexualised substance use in gay bisexual and other men who have sex with men attending sexual health clinics. International Journal of STD \& AIDS, 28(4), 362-366. https://doi.org/ $10.1177 / 0956462416651229$

Hernando Rovirola, C., Ortiz-Barreda, G., Galán Montemayor, J. C., Sabidó Espin, M., \& Casabona Barbarà, J. (2014). Infección VIH/ Sida y otras infecciones de transmisión sexual en la población inmigrante en España: Revisión bibliográfica. Revista Española De Salud Pública, 88(6), 763-781. https://doi.org/10.4321/S113557272014000600009

Hernando, V., Arco, D. A., Alejos, B., Monge, S., Amato-Gauci, A. J., Noori, T., \& Pharris, A. (2015). HIV infection in migrant populations in the European Unionand European Economic Area in 2007-2012: an epidemic on the move. Journal of Acquired Immune Deficiency Syndromes, 70(2), 8.

Hinkin, C. H., Barclay, T. R., Castellon, S. A., Levine, A. J., Durvasula, R. S., Marion, S. D., et al. (2007). Drug use and medication adherence among HIV-1 infected individuals. AIDS and Behavior, 11(2), 185-194. https://doi.org/10.1007/ s10461-006-9152-0.

Hirshfield, S., Remien, R. H., Walavalkar, I., \& Chiasson, M. A. (2004). Crystal methamphetamine use predicts incident STD infection among men who have sex with men recruited online: a nested case-control study. Journal of Medical Internet Research, 6(4). https://doi.org/10.2196/jmir.6.4.e41 
Hoenigl, M., Chaillon, A., Moore, D. J., Morris, S. R., Smith, D. M., \& Little, S. J. (2016). Clear links between starting methamphetamine and increasing sexual risk behavior: a cohort study among men who have sex with men. JAIDS Journal of Acquired Immune Deficiency Syndromes, 71(5), 551-557. https://doi.org/10.1097/ QAI.0000000000000888

Hopwood, M., Lea, T., \& Aggleton, P. (2015). Drug, sex and sociality: Factors associated with the recent sharing of injecting equipment among gay and bisexual men in Australia. International Journal of Drug Policy, 26(2), 210-213. https://doi.org/10.1016/j.drugpo. 2014.10.013

Kramer, S. C., Schmidt, A. J., Berg, R. C., Furegato, M., Hospers, H., Folch, C., \& Marcus, U. (2015). Factors associated with unprotected anal sex with multiple non-steady partners in the past 12 months: Results from the European Men-Who-Have-Sex-WithMen Internet Survey (EMIS 2010). BMC Public Health, 16(1), 47. https://doi.org/10.1186/s12889-016-2691-z

Kumar, S., Rao, P., Earla, R., \& Kumar, A. (2015). Drug-drug interactions between anti-retroviral therapies and drugs of abuse in HIV systems. Expert Opinion on Drug Metabolism \& Toxicology, 11(3), 343-355. https://doi.org/10.1517/17425255.2015.996546

Latini, A., \& Dona', M. G., Alei, L., Colafigli, M., Frasca, M., Orsini, D., Giuliani, M., Morrone, A., Cristaudo, A., \& Zaccarelli, M. (2019). Recreational drugs and STI diagnoses among patients attending an STI/HIV reference clinic in Rome, Italy. Sexually Transmitted Infections, 95(8), 588-593. https://doi.org/10.1136/ sextrans-2019-054043

Martínez-Rebollar, M., De La Mora, L., Campistol, M., Cabrera, B., Bagué, A., De Lazzari, E., Torres, B., González-Cordón, A., Inciarte, A., Ambrosioni, J., Martínez, E., Blanco, J. L., Forns, X., Blanch, J., Mallolas, J., \& Laguno, M. (2021). Impact of Sexualized Substance Use and Other Risk Practices on HCV Microelimination in gbMSM Living with HIV: Urgent Need for Targeted Strategies. Results of a Retrospective Cohort Study. Infectious Diseases and Therapy. https://doi.org/10.1007/ s40121-021-00448-0

Martínez-Rebollar M, Mallolas J, Pérez I, González-Cordón A, Loncà M, Torres B, Rojas JF, Monteiro P, Blanco JL, Martínez E, Gatell JM, Laguno M. (2015). Brote epidémico de hepatitis aguda $C$ en pacientes infectados por el virus de la inmunodeficiencia humana [Acute outbreak of hepatitis $\mathrm{C}$ in human immunodeficiency virusinfected patients]. Enfermedades Infecciosas y Microbiología Clínica, 33(1):3-8. Spanish. https://doi.org/10.1016/j.eimc.2014. 05.013. (Epub 2014 Aug 12. PMID: 25124489)

Maxwell, S., Shahmanesh, M., \& Gafos, M. (2019). Chemsex behaviours among men who have sex with men: A systematic review of the literature. International Journal of Drug Policy, 63, 74-89. https://doi.org/10.1016/j.drugpo.2018.11.014

Mayer, K. H., Colfax, G., \& Guzman, R. (2006). Club drugs and HIV infection: a review. Clinical Infectious Diseases, 42(10), 14631469. https://doi.org/10.1086/503259.

Mercer, C. H., Prah, P., Field, N., Tanton, C., Macdowall, W., Clifton, S., Hughes, G., Nardone, A., Wellings, K., Johnson, A. M., \& Sonnenberg, P. (2016). The health and well-being of men who have sex with men (MSM) in Britain: Evidence from the third National Survey of Sexual Attitudes and Lifestyles (Natsal-3). BMC Public Health, 16(1), 525. https://doi.org/10.1186/s12889-016-3149-z

Ministerio de Sanidad, Consumo y Bienestar Social_CiudadanosVigilancia epidemiológica. (s. f.). https://www.mscbs.gob.es/
ciudadanos/enfLesiones/enfTransmisibles/sida/vigilancia/home. htm. Accessed March 2021

Mora, R. (s. f.). Servicio ChemSex Support: Una respuesta desde y para la comunidad LGTB+ Revista Multidisciplinar del Sida. https:// www.revistamultidisciplinardelsida.com/download/serviciochemsex-support-una-respuesta-desde-y-para-la-comunidad-lgtb/. Accessed March 2021

Muirhead, G. J., Wulff, M. B., Fielding, A., Kleinermans, D., \& Buss, N. (2000). Pharmacokinetic interactions between sildenafil and saquinavir/ritonavir. British Journal of Clinical Pharmacology, 50(2), 99-107. https://doi.org/10.1046/j.1365-2125.2000.00245.x. PMID:10930961;PMCID:PMC2014393

Nichiata, L. Y. I., Bertolozzi, M. R., Takahashi, R. F., \& Fracolli, L. A. (2008). The use of the «vulnerability» concept in the nursing area. Revista Latino-Americana De Enfermagem, 16(5), 923-928. https://doi.org/10.1590/S0104-11692008000500020

Pakianathan, M., Whittaker, W., Lee, M., Avery, J., Green, S., Nathan, B., \& Hegazi, A. (2018). Chemsex and new HIV diagnosis in gay, bisexual and other men who have sex with men attending sexual health clinics. HIV Medicine, 19(7), 485-490. https://doi.org/10. 1111/hiv.12629

Schmidt, A. J., Bourne, A., Weatherburn, P., Reid, D., Marcus, U., \& Hickson, F. (2016). Illicit drug use among gay and bisexual men in 44 cities: Findings from the European MSM Internet Survey (EMIS). International Journal of Drug Policy, 38, 4-12. https:// doi.org/10.1016/j.drugpo.2016.09.007

Sewell, J., Cambiano, V., Miltz, A., Speakman, A., Lampe, F. C., Phillips, A., Stuart, D., Gilson, R., Asboe, D., Nwokolo, N., Clarke, A., Hart, G., \& Rodger, A. (2018). Changes in recreational drug use, drug use associated with chemsex, and HIV-related behaviours, among HIV-negative men who have sex with men in London and Brighton, 2013-2016. Sexually Transmitted Infections, 94(7), 494-501. https:// doi.org/10.1136/sextrans-2017-053439

Sewell, J., Miltz, A., Lampe, F. C., Cambiano, V., Speakman, A., Phillips, A. N., Stuart, D., Gilson, R., Asboe, D., Nwokolo, N., Clarke, A., Collins, S., Hart, G., Elford, J., \& Rodger, A. J. (2017). Poly drug use, chemsex drug use, and associations with sexual risk behaviour in HIV-negative men who have sex with men attending sexual health clinics. International Journal of Drug Policy, 43, 33-43. https://doi. org/10.1016/j.drugpo.2017.01.001

StataCorp. (2019). Stata: Release 16. Statistical Software. College Station, TX: StataCorp LLC., https://www.stata.com

Stardust, Z., Kolstee, J., Joksic, S., Gray, J., \& Hannan, S. (2018). A community-led, harm-reduction approach to chemsex: Case study from Australia's largest gay city. Sexual Health, 15(2), 179. https://doi.org/10.1071/SH17145

Weatherburn, P., Hickson, F., Reid, D., Torres-Rueda, S., \& Bourne, A. (2017). Motivations and values associated with combining sex and illicit drugs ('chemsex') among gay men in South London: Findings from a qualitative study. Sexually Transmitted Infections, 93(3), 203-206. https://doi.org/10.1136/sextrans-2016-052695

Yu, G., Wall, M. M., Chiasson, M. A., \& Hirshfield, S. (2015). Complex Drug Use Patterns and Associated HIV Transmission Risk Behaviors in an Internet Sample of U.S. Men Who Have Sex with Men. Archives of Sexual Behavior, 44(2), 421-428. https://doi.org/ 10.1007/s10508-014-0337-8

Publisher's Note Springer Nature remains neutral with regard to jurisdictional claims in published maps and institutional affiliations. 